\title{
Catalytic Asymmetric and Stereodivergent Oligonucleotide Synthesis
}

Authors: Aaron L. Featherston ${ }^{19 \dagger}$, Yongseok Kwon ${ }^{1 \uparrow}$, Matthew M. Pompeo ${ }^{1 \uparrow}$, Oliver D. Engl ${ }^{2}$, David K. Leahy ${ }^{2 *}$, Scott J. Miller ${ }^{*}$

\section{Affiliations:}

${ }^{1}$ Department of Chemistry, Yale University, P.O. Box 208107, New Haven, Connecticut 065208107, United States of America

2 Process Chemistry Development, Takeda Pharmaceuticals International Co., Cambridge, Massachusetts 02139, United States of America

*Correspondence to: scott.miller@yale.edu \& david.leahy@biohavenpharma.com

Abstract: We report the catalytic stereocontrolled synthesis of dinucleotides. Chiral phosphoric acid (CPA) catalysts are demonstrated to control the formation of stereogenic phosphorous centers during phosphoramidite transfer for the first time. Unprecedented levels of diastereodivergence are also demonstrated, enabling access to either phosphite diastereomer. Notably, two different CPA scaffolds prove essential for achieving stereodivergence: peptide-embedded phosphothreonine-derived CPAs, which reinforce and amplify the inherent substrate preference, and C2-symmetric BINOL-derived CPAs, which completely overturn this stereochemical preference. The presently reported catalytic method does not require stoichiometric activators or chiral auxiliaries and enables asymmetric catalysis with readily available phosphoramidites. The method was applied to the stereocontrolled synthesis of diastereomeric dinucleotides as well as cyclic dinucleotides (CDNs) which are of broad interest in immono-oncology as agonists of the STING pathway.

One Sentence Summary: Chiral Brønsted-acids catalyze the formation of P-stereogenic phosphorous compounds at the P(III) oxidation state, allowing efficient access to oligonucleotide targets.

$\$$ Present address: Department of Chemistry, Sogang University, Seoul 121-742, Korea.

$\dagger$ Present address: Process Research \& Development, AbbVie Inc., 1401 Sheridan Road, North Chicago, IL, 60064.

$\S$ Present address: Biohaven Pharmaceuticals, 215 Church St, New Haven, CT, 06510

"These authors contributed equally to this work. 


\section{Main Text:}

\section{Introduction}

Synthetically modified nucleotides, designed to mimic and interact with their physiological counterparts, continue to grow in importance (1). Examples include cyclic dinucleotides (CDNs), a class of macrocyclic natural products with profound biological significance. The heterodimer 2',3'-cGAMP (Fig. 1A) elicits an immune response through activation of the stimulator of interferon genes (STING) protein (2). This activation pathway is currently being evaluated in multiple clinical studies for oncology therapeutics (3). Chemical modification of the native phosphodiester linkages is a powerful strategy to prepare small molecule therapeutics with increased metabolic stability and therapeutic potential (4). One effective modification is the permutation of the phosphodiester linkage to a phosphorothioate (PS). However, this alteration adds chemical complexity, as it renders the central phosphorus atoms stereogenic. Thus, four possible diastereomers of a phosphorothioate-derived CDN exist, each possessing markedly different biological activities and physical properties (3,5). Most synthetic methods for the preparation of these CDN derivatives rely on nonselective syntheses, requiring tedious reversedphase HPLC purifications to isolate diastereomerically pure analogs in small quantities (6). To date, the only stereoselective synthesis of a modified 3',3'-CDN employs chiral auxiliaries, which despite impressive levels of stereocontrol, are deployed as components of stoichiometric reagents (7). Given the critical importance of these new stereogenic-at-phosphorus compounds, efforts to develop more robust and selective processes to access stereopure cyclic- and antisense oligonucleotides (ASOs) are of broad general interest.

The most general method for the synthesis of PS-modified oligonucleotides employs commercially available P(III)-phosphoramidites and a stoichiometric activator to afford a stochastic mixture of $2^{\mathrm{n}}$ diastereomers (8). The use of chiral auxiliaries thus remains the only viable option to establish reliable stereocontrol (Fig. 1B). In a series of pioneering studies, Wada and coworkers demonstrated a P(III)-stereogenic chiral auxiliary that enabled access to stereochemically pure phosphodiester analogs (9). More recently, Baran and co-workers unveiled a powerful P(V)based approach used for the stereocontrolled synthesis of phosphorothioates $(7,10)$. However, by design, these strategies rely on multi-step syntheses to prepare and install the auxiliaries; a stoichiometric quantity of byproduct is also intrinsic to the approach, as the chiral auxiliary is 
eventually cleaved from the target compound after the stereospecific installation of the Pstereogenic functionality.

Asymmetric catalysis can potentially address the shortcomings of chiral auxiliary-based approaches. Importantly, DiRocco et al. disclosed a multifunctional catalyst to assemble prodrugs at the $\mathrm{P}(\mathrm{V})$ oxidation state through a dynamic kinetic asymmetric transformation (DYKAT) (11), expanding greatly on the general principle of catalytic enantioselective phosphate transfer (12). However, application of this catalytic modality to the formation of stereogenic PS compounds has not yet been disclosed, nor was catalyst-controlled diastereodivergence demonstrated, which is critical in enabling a fully stereocontrolled synthesis of all possible oligonucleotide stereoisomers. Moreover, no catalytic asymmetric method has yet been reported for selective P(III)-based transfers within the context of the widely employed phosphoramidite method for nucleotide synthesis.

Classically, for the synthesis of PS-modified CDNs, the first thiophosphate linkage is often formed via a phosphoramidite coupling from readily available nucleoside fragments. Brønstedacid activators of the $\mathrm{P}(\mathrm{III})$ phosphoramidite, often employed in stoichiometric or superstoichiometric quantities, produce an interconverting mixture of chiral P(III) intermediates, followed by stereorandom nucleophilic displacement to afford a chiral P(III) phosphite intermediate (13). Subsequent oxidative sulfurization affords the desired stereogenic $\mathrm{P}(\mathrm{V})$ species as a mixture of diastereomers. Catalytic stereoselective phosphoramidite transfer would represent a significant step forward if able to harness readily accessible phosphoramidites that are staples of the global oligonucleotide synthesis enterprise. However, catalytic concepts for asymmetric transfer of P(III) phosphoramidites are in their infancy, having been applied only to a small set of enantioselective and site-selective reactions (14). Analogous diastereoselective methods to produce P-stereogenic compounds at the $\mathrm{P}(\mathrm{III})$ oxidation state are absent. Accordingly, we present herein a catalytic synthesis of P(III)-stereogenic compounds based on a previously unknown catalytic approach - the use of chiral phosphoric acid (CPA)-mediated couplings to access stereodefined dinucleotides in a stereocontrolled manner (Fig. 1C). Our mechanistic concept is predicated on a novel mixed-valence $\mathrm{P}(\mathrm{III})-\mathrm{P}(\mathrm{V})$ substrate-catalyst complex (Fig. 1D) that undergoes rapid, pre-stereochemistry determining epimerization at P(III), and is exemplified with synthetic and mechanistic studies below. 


\section{Results and Discussion}

The efficient coupling of nucleoside P(III) phosphoramidites generally requires Brønstedacid activators such as $1 H$-tetrazole or 4,5 -dicyanoimidazole $(8,15,16)$. However, an excess of the acid is required due to catalyst sequestration as the diaalkylammonium salt resulting from the formation of stoichiometric dialkylamine. Recent advances enable the use of these activators in sub-stoichiometric quantities (8), yet none has yet addressed the challenge of stereocontrol. Perhaps the sole example of catalytic asymmetric phosphitylation employed tetrazoylalaninebased catalysts in the desymmetrization of D-myo-inositol via enantioselective phosphoramidite transfer $(14 a)$. In these reactions, the chiral tetrazole serves as a Brønsted-acid in conjunction with $10 \AA \AA$ molecular sieves to scavenge the liberated diethylamine, thereby facilitating catalyst turnover. This result grounded the notion that chiral Brønsted acids could serve as effective catalysts for stereocontrolled oligonucleotide synthesis.

Over the past decade, $\mathrm{C}_{2}$-symmetric CPAs have emerged as powerful Brønsted acid catalysts for myriad asymmetric transformations (17). Recent efforts in our group have focused on the development of peptide-embedded phosphothreonine (pThr) as a new class of CPA catalyst (18). In order to assess the ability of these CPAs to affect an asymmetric phosphitylation, we began with the $2^{\prime}$ to $5^{\prime}$ coupling of guanosine phosphoramidite 1 (ca. 1:1 dr) and adenosine derivative 2 (Fig. 2A). Indeed, simple phosphoric acids catalyze the coupling of $\mathbf{1}$ and $\mathbf{2}$ to provide a $\mathrm{P}(\mathrm{III})$ dinucleotide intermediate, which then undergo a stereoretentive oxidation with $t$ - $\mathrm{BuOOH}$ to afford the desired stereogenic phosphate ester 3. Importantly, phenyl isocyanate was found to be an effective scavenger of the liberated diisopropylamine by irreversible formation of a phenyl urea adduct, thereby enabling catalyst turnover (19), while the use of $3 \AA$ molecular sieves prevented any acid catalyzed hydrolysis of phosphoramidite 1 (14a).

Catalyst optimization. In order to assess the feasibility of stereocontrol, we evaluated the two families of CPAs, and compared the results with those obtained with diphenylphosphoric acid (DPP), an achiral catalyst used to benchmark the intrinsic selectivity innate to the chiral substrates. Evaluation of pThr-derived catalysts quickly revealed that catalysts biased toward the $\beta$-turn structure with a ${ }^{D}$ Pro and Aib motif in the $i+1$ and $i+2$ positions, respectively, emerged as a selective catalysts (Fig. 2A, entries 1-11) (20, 21). In particular, catalyst P3 (entry 3; 20 mol\%), 
afforded the product in 77\% yield and 85:15 dr, amplifying the $S_{\mathrm{P}}$ diastereomer (relative to the 77:23 ratio obtained with DPP; entry 21). Two notable features of this catalyst are: 1) the diaminopropionic $i+3$ residue, which often captures additional non-covalent interactions between catalysts and substrates (18b), and 2) the allo stereochemistry of the threonine residue (18c). Further modifications to the catalyst architecture did not lead to a profound increase in selectivity (P4-P8). However, several other variables influence the stereochemical outcome. By reducing the reaction concentration to $0.04 \mathrm{M}$ in acetonitrile, the selectivity was improved to 91:9 $\mathrm{dr}$ (entry 4); lowering the reaction temperature to $4{ }^{\circ} \mathrm{C}$ afforded the product in $79 \%$ isolated yield and 94:6 dr (entry 10). Scaling up to $0.1 \mathrm{mmol}$ scale under a normalized set of reaction conditions (Fig. 3A), the product was obtained in $67 \%$ yield and $88: 12 \mathrm{dr}$.

Given the dramatic impact of P-stereogenicity on the efficacy of oligonucleotide-based therapeutics $(3,5)$ we sought a complementary, stereodivergent phosphitylation catalyst (22). Notably, the CPA chemotype based on the C2-symmetric BINOL scaffold provided this outcome (23). Initially, $(R)$-TRIP (B1) was evaluated under the standard reaction conditions and 15 dinucleotide 3 was obtained in 26\% yield and with a modest, but diastereomerically reversed 45:55 dr (Fig. 2B, entry 12), favoring slightly the alternative $R_{\mathrm{P}}$ diastereomer. Strikingly, when employing (S)-B1 as the catalyst, a marked improvement in yield and selectivity was observed (74\% yield and 8:92 dr; entry 13), dramatically enhancing the selectivity for the opposite diastereomer with respect to that observed with the pThr-based catalysts. A survey of BINOLCPAs revealed the tricyclohexyl catalyst $(S)$-B7 to be superior (entries 14-19), affording the $\left(R_{\mathrm{P}}\right)$ configured product in $63 \%$ yield and 1:99 dr. The enantiomeric catalyst $(R)-\mathbf{B} 7$ is much less selective (43:57 dr), but still favors the same $R_{\mathrm{P}}$ diastereomer. It is thus demonstrated that the two distinct catalyst scaffolds, the pThr-based CPA framework and the BINOL-derived CPA architecture, enable catalytic asymmetric phosphoramidite couplings that exhibit significant degrees of stereodivergence.

Mechanistic hypothesis. One hallmark of these reactions is the stereoconvergent transformation of a diastereomeric mixture of phosphoramidite stereoisomers (1) to a highly diastereoenriched phosphite product, which is then oxidized stereospecifically to the corresponding stereogenic phosphate $\left(\left(R_{\mathrm{P}}\right)-\mathbf{3}\right.$ or $\left.\left(S_{\mathrm{P}}\right)-\mathbf{3}\right)$. In analogy to the widely accepted mechanism for $1 H$-tetrazole $(8,15)$, we envisioned that the phosphoric acid catalyst acts as both an acid and nucleophilic catalyst after proton transfer to displace diisopropylamine (Fig. 1D). 
Critically, the resulting mixed-valence $\mathrm{P}(\mathrm{III})-\mathrm{P}(\mathrm{V})$ intermediate could undergo rapid epimerization via displacement with an additional molecule of catalyst or, alternatively, via intramolecular inversion with the adjacent $\mathrm{P}=\mathrm{O}$. The stereochemical outcome of the coupling reactions thus tracks with the relative magnitude of the displacement rate constants $k_{1}$ and $k_{2}$ in a typical Curtin-Hammett type regime characteristic of a dynamic kinetic asymmetric transformation (DYKAT) mechanism (24).

To validate our assumptions and probe the mechanistic hypothesis, we separated the phosphoramidite diastereomers (1) by reversed phase chromatography (Fig. 2C). The resulting diastereomerically pure phosphoramidites $\left(\mathbf{1}_{\text {Fast }}\right.$ and $\left.\mathbf{1}_{\text {Slow }}\right)$ were then subjected to the optimized reaction conditions for each catalyst: P3, $(S)$-B7 and DPP. The stereochemical outcome of dinucleotide $\mathbf{3}$ was found to be independent of the starting $\mathrm{dr}$ of $\mathbf{1}$, as the catalysts converted either diastereomer of $\mathbf{1}$ to either $\left(R_{\mathrm{P}}\right)-\mathbf{3}$ or $\left(S_{\mathrm{P}}\right)-\mathbf{3}$ with the same diastereoselectivity.

Substrate scope. With a pair of stereodivergent catalysts in hand, we explored the scope of the coupling with a selection of representative substrates (Fig. 3). Notably, by controlling the stereochemistry at $\mathrm{P}(\mathrm{III})$, we can access a variety of $\mathrm{P}(\mathrm{V})$ products. For example, treatment of the intermediate phosphite with $t$-BuOOH affords the phosphate 3, while sulfurization using phenylacetyl disulfide (PADS) affords the phosphorothioate 4 (25). Notably, the loading of (S)B7 could be reduced to 5 mol\% to produce $\left(S_{\mathrm{P}}\right)-4$ in $57 \%$ yield at $98: 2 \mathrm{dr}(26)$ by increasing the reaction concentration to $0.40 \mathrm{M}$. As methods for the synthesis of selenophosphate (27), boranophosphate (28), phosphoramidite (29), and methyl phosphonate (30) from the P(III) oxidation state have all been reported, this new catalytic protocol enables access to a wide range of functionalized $\mathrm{P}(\mathrm{V})$ products (Fig 1B).

In addition to isopropylidene adenosine (3), deoxyadenosine (5), and C2'-fluorodeoxyadenosine (6) were well tolerated. In each case, analogous diastereodivergence was observed 25 with enhancement of intrinsic selectivity with catalyst $\mathbf{P 3}$ and near-total reversal of selectivity with catalyst $(S)$-B7. A particularly striking result is obtained when $2^{\prime}, 3^{\prime}$-unprotected adenosine is employed as the nucleophilic coupling partner. In this case, a highly site- and diastereoselective phosphorylation is achieved with $(S)$-B7, selecting for a single product (7) over five possible alternative stereo- or regioisomers of monocoupled product. In contrast, a complex mixture of products was obtained when DPP is used as the catalyst, as shown in the crude ${ }^{31} \mathrm{P}$ NMR spectra 
(Fig. 3B). Other ribonucleosides could also be coupled to guanosine $\mathbf{1}$ in good yields and selectivity (8-10). Interestingly, selectivities were lower when the role of the coupling partners were reversed; when adenosine-derived phosphoramidite was coupled to the 5'-OH of guanosine acetonide, both catalysts favor slightly the same (unassigned) diastereomer of dinucleotide 11. Furthermore, the case of uridine illustrates the potential for catalyst refinement in situations where the selectivity for new substrates is modest. For example, in the case of substrate 12, BINOLderived catalyst $(S)$-B7 delivers the product with an unimpressive dr of 47:53, yet an alternative CPA $(S)$-B8 delivers the product with an excellent 3:97 dr. Peptide-derived catalyst P3 did slightly enhance the selectivity for the antipodal diastereomer in this case, however with lower selectivity than observed with the model substrate $(73: 27 \mathrm{dr})$.

Taken together, our scope studies reveal that the diastereodivergent catalysis we have observed can be applied to other nucleobase pairs. The efficacy of the catalysts optimized for the coupling of guanosine phosphoramidite $\mathbf{1}$ and adenosine $\mathbf{2}$ appears to be more strongly dependent on the structure of the electrophile than the nucleophile. Selectivities remain high when coupling $\mathbf{1}$ to an array of different nucleosides (3-10) yet decrease when coupling other phosphoramidites $(\mathbf{1 1 , 1 2})$. Nonetheless, while neither universal catalysts nor a complete set of catalysts for all possible couplings is yet in hand, the concepts we have demonstrated seem generalizable for this very ambitious longer-term goal.

CDN synthesis. In order to address the reported synthetic inefficiencies associated with both non-selective nucleoside couplings and (super)stoichiometric activators and auxiliaries, we then prepared stereodefined CDNs in a catalyst-controlled manner $(2,6)$. We envisioned a concise asymmetric approach using this newly developed stereoselective phosphoramidite coupling between 1 and 13, followed by a H-phosphonate macrocyclization to access phosphorothioate 16 with the desired phosphorus stereochemistry (Fig. 4) (31). Initially, coupling of 1 and $13 \cdot \mathrm{Et}_{3} \mathrm{~N}$ under the optimized catalytic conditions revealed a disappointing level of selectivity (Fig. 4A). Control experiments in the absence of chiral catalyst revealed a fast non-selective background reaction, likely a result of autocatalysis promoted by the triethylammonium cation $(\mathrm{p} K \mathrm{a}(\mathrm{DMSO})=$ 9.0), which outcompetes the catalyzed process (see SI). (32)

To circumvent this autocatalysis, we prepared a selection of alkali-metal phosphonate salts via ion-exchange and evaluated the efficacy of these new salts. When the reaction was performed 
with $13 \cdot \mathrm{Na}$ in the absence of catalyst, the product was obtained in $23 \%$ yield after $24 \mathrm{~h}$, compared to $46 \%$ with $13 \cdot \mathrm{Et}_{3} \mathrm{~N}$ suggesting a suppressed background reaction (see SI). With our previously optimized catalysts, we found that the selectivity was dependent on both the counterion and the catalyst structure. Using pThr catalyst $\mathbf{P 3}$, we found the $\mathrm{Cs}^{+}$phosphonate salt afforded the highest selectivity for the $R_{\mathrm{P}}$ diastereomer of $\mathbf{1 4}$ (10:90 dr) (26). Furthermore, catalyst $(S)$-B8 emerged from a catalyst screen as the most selective for the $S_{\mathrm{P}}$ diastereomer using the $\mathrm{Li}^{+}$salt of 13 (74:26 dr). With further refinement, the use of MeCN/DMF at $4{ }^{\circ} \mathrm{C}$ led to increased selectivity $(77: 23 \mathrm{dr})$ due to the increased solubility of the $\mathrm{Li}^{+}$salt under the reaction conditions. It is noteworthy that with these highly functionalized zwitterionic substrates, the peptidic catalyst $\mathbf{P 3}$ actually outperforms the BINOL-derived catalyst $(S)$-B8, in contrast to the less functionalized substrates presented in Fig. 3. Thus, catalyst tuning and counterion optimization enabled the preparation of each diastereomer of dinucleotide 14 with high diastereoselectivity.

In order to complete the syntheses of stereopure CDNs (33), we carried out the couplings of 1 and $13 \cdot \mathrm{Cs}$ with $\mathbf{P 3}$ on a $3.0 \mathrm{mmol}$ scale, to isolate $>2$ grams of crude $\left(R_{\mathrm{P}}\right)-\mathbf{1 4}$ after a simple crystallization. Site-selective hydrolysis of the disilane at $\mathrm{C}^{\prime}$ with aqueous trifluoroacetic acid (TFA) then afforded the macrocyclization precursor $\left(R_{\mathrm{P}}\right)-\mathbf{1 5}$ in 30\% yield and 1:99 dr over two steps after flash chromatography. When subjected to diphenyl phosphoryl chloride (DPPC) with 2,6-lutidine as the base and $20 \mathrm{~mol} \% \mathrm{~N}$-methylimidazole (NMI) as a nucleophilic catalyst in dichloromethane, $\left(R_{\mathrm{P}}, R_{\mathrm{P}}\right)-\mathbf{1 6}$ could be obtained with high diastereoselectivity $(>90: 10 \mathrm{dr})$ and isolated in pure form in $21 \%$ yield $(34,35)$. Following global deprotection, the final CDN 2',3'$\mathrm{cG}^{\mathrm{S}} \mathrm{A}^{\mathrm{S}} \mathrm{MP}\left(\left(R_{\mathrm{P}}, R_{\mathrm{P}}\right)-17\right)$ was isolated as a single diastereomer via crystallization from acetone in $75 \%$ yield and high purity over two steps. The $\left(2^{\prime}-5^{\prime}\right) S_{\mathrm{P}},\left(3^{\prime}-5^{\prime}\right) R_{\mathrm{P}}$ diastereomer could also be obtained in high selectivity through a similar sequence by employing $(S)$-B8 as a catalyst with 13-Li (Fig. 4C). The relative stereochemical configuration at phosphorus of $\left(R_{\mathrm{P}}, R_{\mathrm{P}}\right)-17$ and $\left(S_{\mathrm{P}}, R_{\mathrm{P}}\right)$-17 was determined by measuring the HPLC elution order and comparison to the work of Lim and Kim (36). Thus, peptide-derived catalyst P3 selects for the $\left(R_{\mathrm{P}}\right)$-configured phosphorothioate, whereas BINOL-derived catalysts $(S)$-B7 and $(S)$-B8 select for the $\left(S_{\mathrm{P}}\right)$ configured phosphorothioate. The relative configurations of the 2',5'-linked dinucleotide substrates 3-10 and 12 were thus assigned by analogy (Fig 3).

\section{Conclusion}


CPAs based on both peptidic frameworks and C2-symmetric BINOL-derived scaffolds catalyze phosporamidite coupling reactions with substantial control of stereochemistry at phosphorus (III). Their effectiveness, and indeed their complementarity, are revealed in their capacity to dictate stereodivergence in coupling reactions with readily available nucleotide reaction partners. These catalysts were applied to the stereocontrolled synthesis of CDNs, which not only demonstrates streamlined access to these compounds, but also reveals a capacity for these catalytic reactions to be optimized in the presence of highly functionalized salt forms of nucleotide substrates. Overall, each class of catalyst, and the CPA framework itself, unambiguously provides a new catalytic approach to the synthesis of P-stereogenic nucleotide derivatives, which is of broad fundamental significance and utility.

\section{References and Notes:}

1. L. P. Jordheim, D. Durantel, F. Zoulim, C. Dumontet, Advances in the development of nucleoside and nucleotide analogues for cancer and viral diseases. Nat. Rev. Drug Discov. 12, 447-464 (2013).

2. (a) P. Clivio, S. Coantic-Castex, D. Guillaume, (3'-5')-cyclic dinucleotides: Synthetic strategies and biological potential. Chem. Rev. 113, 7354-7401 (2013). (b) H. Ishikawa, G. N. Barber, STING is an endoplasmic reticulum adaptor that facilitates innate immune signaling. Nature 455, 674-678 (2008). (c) D. Burdette, K. M. Monroe, K. Sotelo-Troha, J. S. Iwig, B. Eckert, M. Hyodo, Y. Hayakawa, R. E. Vance, STING is a direct innate immune sensor of cyclic di-GMP Nature 478, 515-518 (2011). (d) L. Sun, J. Wu, F. Du, X. Chen, Z. J. Chen, Cyclic GMP-AMP Synthase Is a Cytosolic DNA Sensor That Activates the Type I Interferon Pathway Science 339, 786-791 (2013).

3. H. Zhang, Q. D. You, X. L. Xu, Targeting Stimulator of Interferon Genes (STING): A Medicinal Chemistry Perspective. J. Med. Chem. 63, 3785-3816 (2020).

4. L. Li, Q. Yin, P. Kuss, Z. Maliga, J. L. Millán, H. Wu, T. J. Mitchison, Hydrolysis of 2'3'-cGAMP by ENPP1 and design of nonhydrolyzable analogs. Nat. Chem. Biol. 10, 1043-1048 (2014).

5. (a) A. V. Lebedev, E. Wickstrom, The chirality problem in P-substituted oligonucleotides. Perspect. Drug Discov. Des. 4, 17-40 (1996). (b) B. Roy, A. Depaix, C. Périgaud, S. Peyrottes, Recent Trends in Nucleotide Synthesis. Chem. Rev. 116, 7854-7897 (2016). (c) N. Iwamoto, D. C. D. Butler, N. Svrzikapa, S. Mohapatra, I. Zlatev, D. W. Y. Sah, S. Meena, M. Standley, G. Lu, L. H. Apponi, M. Frank-Kamenetsky, J. J. Zhang, C. Vargeese, G. L. Verdine, Control of phosphorothioate stereochemistry substantially increases the efficacy of antisense oligonucleotides. Nat. Biotechnol. 35, $845-851$ (2017).

6. T. Lioux, M. A. Mauny, A. Lamoureux, N. Bascoul, M. Hays, F. Vernejoul, A. S. Baudru, C. Boularan, J. Lopes-Vicente, G. Qushair, G. Tiraby, Design, Synthesis, and Biological Evaluation of Novel Cyclic 
Adenosine-Inosine Monophosphate (cAIMP) Analogs That Activate Stimulator of Interferon Genes (STING). J. Med. Chem. 59, 10253-10267 (2019).

7. K. W. Knouse, J. N. DeGruyter, M. A. Schmidt, B. Zheng, J. C. Vantourout, C. Kingston, S. E. Mercer, I. M. Mcdonald, R. E. Olson, Y. Zhu, C. Hang, J. Zhu, C. Yuan, Q. Wang, P. Park, M. D. Eastgate, P. S. Baran, Unlocking P(V): Reagents for Chiral Phosphorothioate Synthesis. Science 361, 1234-1238 (2018).

8. Y. Hayakawa, M. Kataoka, Preparation of Short Oligonucleotides via the Phosphoramidite Method Using a Tetrazole Promoter in a Catalytic Manner J. Am. Chem. Soc. 119, 11758-11762 (1997).

9. (a) N. Oka, T. Wada, K. Saigo, Diastereocontrolled Synthesis of Dinucleoside Phosphorothioates Using a Novel Class of Activators, Dialkyl(cyanomethyl)ammonium Tetrafluoroborates. $\mathrm{J}$. Am. Chem. Soc. 124, 4962-4963 (2002). (b) N. Oka, T. Wada, K. Saigo, An Oxazaphospholidine Approach for the Stereocontrolled Synthesis of Oligonucleoside Phosphorothioates J. Am. Chem. Soc. 125, 8307-8317 (2003).

10. D. Xu, N. Rivas-Basco, N. M. Padial, K. W. Knouse, B. Zheng, J. C. Vantourout, M. A. Schmidt, M. D. Eastgate, P. S. Baran, Enantiodivergent Formation of C-P Bonds: Synthesis of P-Chiral Phosphines and Methylphosphonate Oligonucleotides. J. Am. Chem. Soc. 142, 5785-5792 (2020).

11. D. A. DiRocco, Y. Ji, E. C. Sherer, A. Klapars, M. Reibarkh, J. Dropinski, R. Mathew, P. Maligres, A. M. Hyde, J. Limanto, A. Brunskill, R. T. Ruck, L. C. Campeau, I. W. Davies, A Multifunctional Catalyst That Stereoselectively Assembles Prodrugs. Science 356, 426-430 (2017).

12. (a) B. R. Sculimbrene, S. J. Miller, Discovery of a Catalytic Asymmetric Phosphorylation through Selection of a Minimal Kinase Mimic: A Concise Total Synthesis of D-myo-Inositol-1-Phosphate. $J$. Am. Chem. Soc. 123, 10125-10126 (2001). (b) C. M. Longo, Y. Wei, M. F. Roberts, S. J. Miller, Asymmetric Syntheses of L,L- and L,D-Di-myo-Inositol-1,1'-Phosphate and their Behavior as Stabilizers of Enzyme Activity at Extreme Temperatures. Angew. Chem. Int. Ed. 48, 4158-4161 (2009).

13. (a) B. H. Dahl, J. Nielsen, O. Dahl, Mechanistic Studies on the Phosphoramidite Coupling Reaction in Oligonucleotide Synthesis. Nucleic Acids Res. 15, 1729-1743 (1987). (b) M. A. Russell, A. P. Laws, J. H. Atherton, M. I. Page, The Mechanism of the Phosphoramidite Synthesis of Polynucleotides. Org. Biomol. Chem. 6, 3270-3275 (2008).

14. (a) P. A. Jordan, K. J. Kayser-Bricker, S. J. Miller, Asymmetric Phosphorylation through Catalytic P(III) Phosphoramidite Transfer: Enantioselective Synthesis of D-Myo-Inositol-6-Phosphate. Proc. Natl. Acad. Sci. U. S. A. 107, 20620-20624 (2010). (b) P. A. Jordan, S. J. Miller, An Approach to the Site-Selective Deoxygenation of Hydroxy Groups Based on Catalytic Phosphoramidite Transfer. Angew. Chem. Int. Ed. 51, 2907-2911 (2012).

15. Y. Hayakawa, R. Kawai, A. Hirata, J. I. Sugimoto, M. Kataoka, A. Sakakura, M. Hirose, R. Noyori, Acid/Azole Complexes as Highly Effective Promoters in the Synthesis of DNA and RNA Oligomers via the Phosphoramidite Method. J. Am. Chem. Soc. 123, 8165-8176 (2001). 
16. C. Vargeese, J. Carter, J. Yegge, S. Krivjansky, A. Settle, E. Kropp, K. Peterson, W. Pieken, Efficient Activation of Nucleoside Phosphoramidites with 4,5-Dicyanoimidazole during Oligonucleotide Synthesis. Nucleic Acids Res. 26, 1046-1050 (1998).

17. D. Parmar, E. Sugiono, S. Raja, M. Rueping, Complete Field Guide to Asymmetric BINOL-Phosphate Derived Brønsted Acid and Metal Catalysis: History and Classification by Mode of Activation; Brønsted Acidity, Hydrogen Bonding, Ion Pairing, and Metal Phosphates. Chem. Rev. 114, 9047-9153 (2014).

18. (a) C. R. Shugrue, S. J. Miller, Phosphothreonine as a Catalytic Residue in Peptide-Mediated Asymmetric Transfer Hydrogenations of 8-Aminoquinolines Angew. Chem. Int. Ed. 54, 11173-11176 (2015). (b) A. L. Featherston, C. R. Shugrue, B. Q. Mercado, S. J. Miller, Phosphothreonine (pThr)Based Multifunctional Peptide Catalysis for Asymmetric Baeyer Villiger Oxidations of Cyclobutanones ACS Catalysis, 9, 242-252 (2019). (c) Y. Kwon, J. Li, J. P. Reid, J. M. Crawford, R. Jacob, M. S. Sigman, F. D. Toste, S. J. Miller, Disparate Catalytic Scaffolds for Atroposelective Cyclodehydration. J. Am. Chem. Soc. 141, 6698-6705 (2019).

19. P. B. Brady, E. M. Morris, O. S. Fenton, B. R. Sculimbrene, Efficient catalyst turnover in the phosphitylation of alcohols with phosphoramidites. Tetrahedron Lett. 50, 975-978 (2009).

20. A. J. Metrano, C. R. Shugrue, B. Kim, A. J. Chinn, E. A. Stone, S. J. Miller, Asymmetric Catalysis Mediated by Synthetic Peptides, Version 2.0: Expansion of Scope and Mechanisms. Chem. Rev. 120, In Press (2020).

21. T. S. Haque, J. C. Little, S. H. Gellman, Stereochemical Requirements for $\beta$-Hairpin Formation: Model Studies with Four-Residue Peptides and Depsipeptides. J. Am. Chem. Soc. 118, 6975-6985 (1996).

22. S. Krautwald, E. M. Carreira, Stereodivergence in Asymmetric Catalysis. J. Am. Chem. Soc. 139, 5627-5639, (2017).

23. (a) T. Akiyama, J. Itoh, K. Yokota, K. Fuchibe, Enantioselective Mannich-Type Reaction Catalyzed by a Chiral Brønsted Acid. Angew. Chem. Int. Ed. 43, 1566-1568 (2004). (b) D. Uraguchi, M. Terada, Chiral Brønsted Acid-Catalyzed Direct Mannich Reactions via Electrophilic Activation. J. Am. Chem. Soc. 126, 5356-5357 (2004).

24. (a) J. Steinreiber, K. Faber, H. Griengl, Chem. Eur. J. 14, 8060-8072 (2008). (b) W. B. Farnham, R. A. Lewis, R. K. Murray Jr., K. Mislow, J. Am. Chem. Soc. 92, 5808-5809 (1970). (c) M. Dutartre, J. Bayardon, S. Jugé, Chem. Soc. Rev. 45, 5771-5794 (2016)

25. J. L. Scotson, B. I. Andrews, P. A. Laws, M. I. Page, Phosphorothioate Anti-Sense Oligonucleotides: The Kinetics and Mechanism of the Generation of the Sulfurising Agent from Phenylacetyl Disulfide (PADS). Org. Biomol. Chem. 14, 8301-8308 (2016).

26. According to the Cahn-Ingold-Prelog (CIP) priority rules, phosphate and its corresponding thiophosphate analogue have opposite $R / S$ stereochemical assignments for the same absolute stereochemical configuration. That is to say, the $\left(R_{\mathrm{P}}\right)$-phosphate has the same absolute stereochemical assignment as the $\left(S_{\mathrm{P}}\right)$-thiophosphate. 
27. W. J. Stec, G. Zon, W. Egan, Automated Solid-Phase Synthesis, Separation, and Stereochemistry of Phosphorothioate Analogues of Oligodeoxyribonucleotides. J. Am. Chem. Soc. 106, 6077-6079 (1984).

28. R. I. Hara, T. Saito, T. Kogure, Y. Hamamura, N. Uchiyama, Y. Nukaga, N. Iwamoto, T. Wada, Stereocontrolled Synthesis of Boranophosphate DNA by an Oxazaphospholidine Approach and Evaluation of Its Properties. J. Org. Chem. 84, 7971-7938 (2019).

29. J. Nielsen, M. H. Caruthers, Directed Arbuzov-Type Reactions of 2-Cyano-1,1-dimethylethyl Deoxynucleoside Phosphites J. Am. Chem. Soc. 110, 6275-6276 (1988).

30. F. Seela, U. Kretschmer, Diastereomerically Pure $R_{P}$ and $S_{P}$ Dinucleoside H-Phosphonates: The Stereochemical Course of Their Conversion into P-Methylphosphonates, Phosphorothioates, and [oxygen-18] Chiral Phosphates. J. Org. Chem. 56, 3861-3869 (1991).

31. B. L. Gaffney, E. Veliath, J. Zhao, R. A. Jones, One-Flask Syntheses of c-Di-GMP and the $[R \mathrm{p}, R \mathrm{p}]$ and $[R \mathrm{p}, \mathrm{Sp}]$ Thiophosphate Analogues. Org. Lett. 12, 3269-3271 (2010).

32. B. L. Gaffney, R. A. Jones, One-Flask Synthesis of Cyclic Diguanosine Monophosphate (c-Di-GMP). Curr. Protoc. Nucleic Acid Chem. 1, 1-7 (2012).

33. M. Yoshikawa, M. Saitoh, T. Kato, Y. Yoshitomi, T. Seki, Y. Nakagawa, Y. Tominari, M. Seto, Y. Sasaki, M. Okaniwa, T. Oda, A. Shibuya, K. Hidaka, Z. Shiokawa, S. Murata, A. Okabe, Y. Nakada, M. Mochizuki, B. Freeze, T. Tawaraishi, Y. Wada, P. Greenspan, Takeda Pharmaceutical Company Ltd. "Cyclic Dinucleotides as STING (Stimulator of Interferon Genes) Agonists." WO2018100558, (2018).

34. M. Sobkowski, J. Stawinski, A. Kraszewski, Stereochemistry of Internucleotide Bond Formation by the H-Phosphonate Method. 5. The Role of Brønsted and H-Bonding Base Catalysis in Ribonucleoside H-Phosphonate Condensation-Chemical and Stereochemical Consequences. Nucleos. Nucleot. Nucl. Acids 29, 628-645 (2010).

35. N. Powles, J. Atherton, M. I. Page, Reactive Intermediates in the H-Phosphonate Synthesis of Oligonucleotides. Org. Biomol. Chem. 10, 5940-5947 (2012).

36. J. Lim, H.-Y. Kim, Novel Applications of Biocatalysis to Stereochemistry Determination of 2',3'cGAMP Bisphosphorothioate (2',3'-cGSASMP). ACS Omega 5, 14173-14179 (2020).

Acknowledgments: We thank N. Ichiishi (Takeda), K. Murai (Takeda), and P. Rapp for helpful discussions; E. Paulson for assistance with nuclear magnetic resonance spectroscopy; F. Menges for assistance with mass spectroscopy; and B. Mercado for X-ray analysis. We also thank J. Lim (Merck) and H.-Y. Kim (Merck) for providing additional information regarding HPLC methods to assist in the stereochemical assignment of $2^{\prime}, 3^{\prime}-\mathrm{cG}^{\mathrm{S}} \mathrm{A}^{\mathrm{S}} \mathrm{MP}$. Funding: Support for this work was provided by Takeda Pharmaceuticals International Co. and the National Institute of General 
Medical Sciences (NIH grant R35 GM132092 to SJM). Author contributions: All authors contributed to the conceptualization of the project, the planning of experiments, interpretation of results and made intellectual contributions. D.K.L. and S.J.M. directed the research. Y.K., A.L.F., and M.M.P. conducted the experiments. The manuscript was written through contributions from all authors. Competing interests: The authors declare no competing interests. Data and materials availability: Crystallographic data are available free of charge from the Cambridge Crystallographic Data Centre under accession numbers CCDC deposition number 2040367. All experimental data are available in the main text or the supplementary materials.

\section{Supplementary Materials:}

Materials and Methods

Figures S1 to S24

Tables S1 to S10

References (1-22)

$15 \quad$ NMR Spectra 
A CDNs: STING antagonists

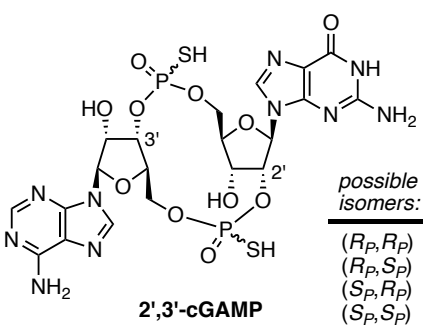

- Potential therapeutic agents

- Poor stereoconrolled syntheses

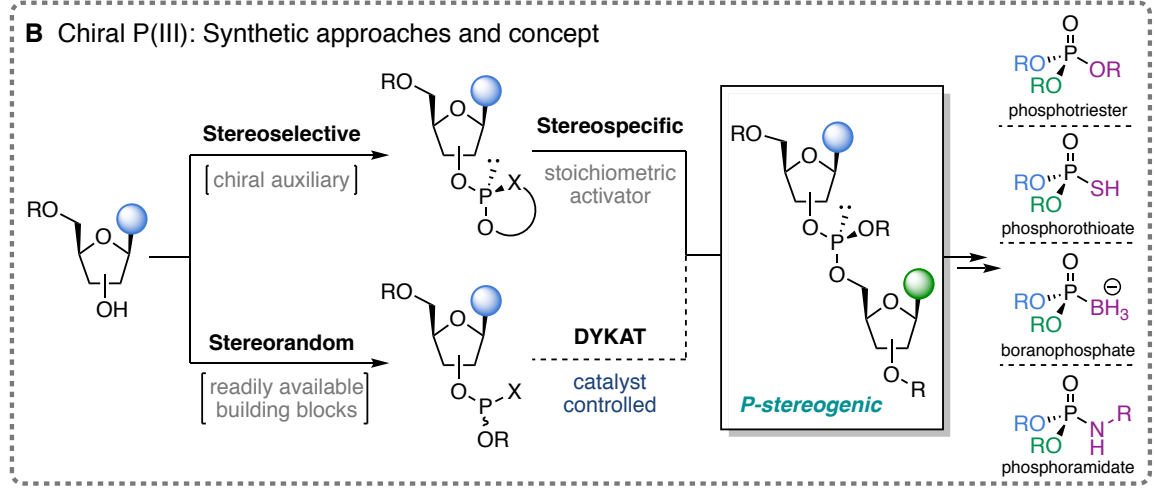

phosphoramidate

C This work: Catalytic stereocontrolled oligonucleotide synthesis

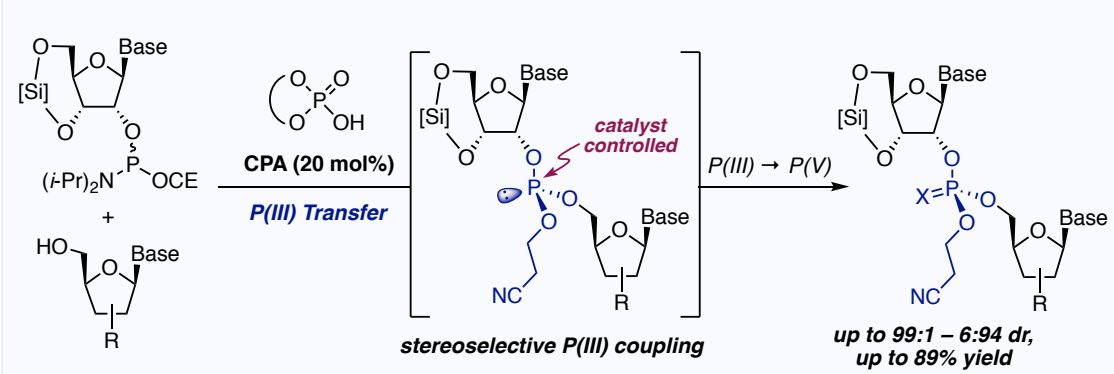

Classes of chiral phosphoric acids

- Brønsted-acid activator

- No stoichiometric auxiliaries

- High stereoselectivities
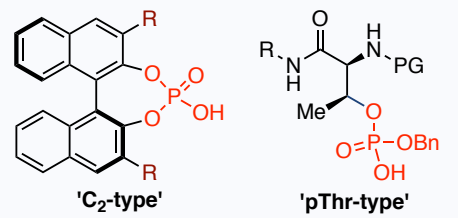

up to $89 \%$ yield

D Proposed DYKAT mechanism of the CPA-catalyzed phosphoramidite coupling via mixed valence $\mathrm{P}(\mathrm{III})-\mathrm{P}(\mathrm{V})$ intermediate

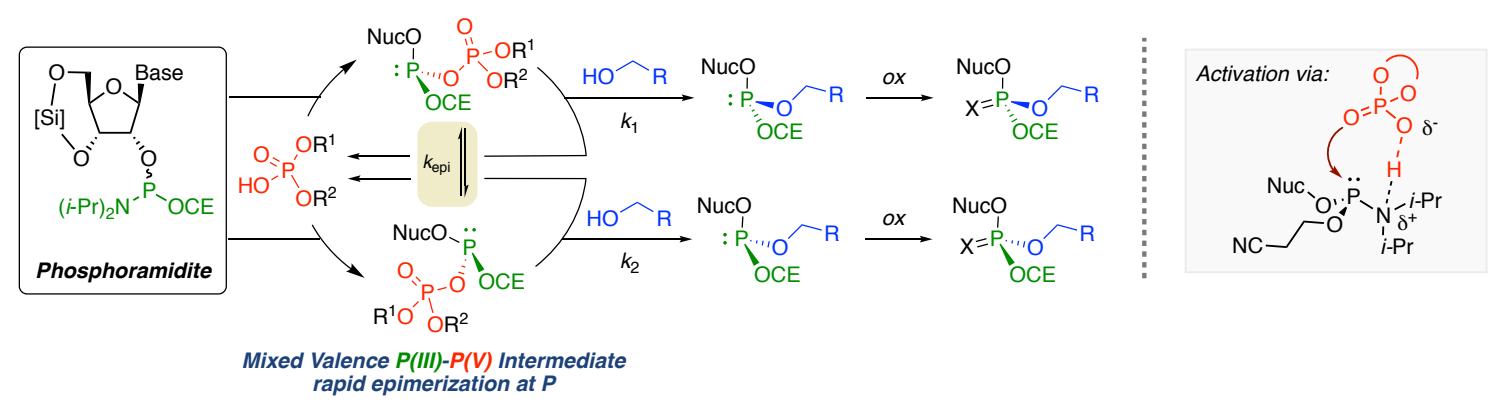

Fig. 1. Background and reaction development. (A) Structure of phosphorothioate cyclic dinucleotide (CDN). (B) Strategies towards the stereoselective synthesis of P(III) compounds used in oligonucleotide synthesis. (C) Brønsted-acid catalyzed dynamic asymmetric transformation of phosphoramidites for the synthesis of stereogenic P(III) compounds. [HA], activator; Nuc, nucleophile. (D) Proposed mechanism for CPA-catalyzed activation of phosphoramidite and epimerization of P-stereogenic center. 
A 'pThr-type' catalyst optimization

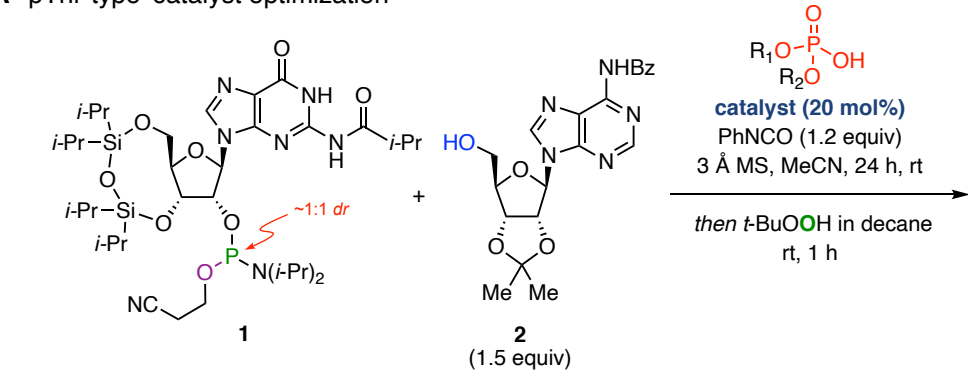

\begin{tabular}{|c|c|c|c|c|c|c|c|c|c|}
\hline \multirow{2}{*}{ entry } & \multicolumn{5}{|c|}{ catalyst } & \multirow{2}{*}{$\begin{array}{c}\text { Temp. } \\
\left({ }^{\circ} \mathrm{C}\right)\end{array}$} & \multirow{2}{*}{$\begin{array}{l}\text { Conc. } \\
\text { [M] }\end{array}$} & \multirow{2}{*}{$\begin{array}{c}\text { Yield } \\
(\%)\end{array}$} & \multirow{2}{*}{$\begin{array}{c}\mathrm{dr} \\
\left(S_{\mathrm{P}}: R_{\mathrm{P}}\right)\end{array}$} \\
\hline & & $i$ & $\mathrm{i}+1$ & $i+2$ & $i+3$ & & & & \\
\hline 1 & P1 & Fmoc-pThr(Bn) & DPro & Aib & $\mathrm{Dap}(\mathrm{Ac})-\mathrm{NMe}_{2}$ & $\mathrm{rt}$ & 0.10 & 78 & $70: 30$ \\
\hline 2 & P2 & Fmoc-pThr(Bn) & DPro & Aic & $\operatorname{Dap}(\mathrm{Ac})-\mathrm{NMe}_{2}$ & $\mathrm{rt}$ & 0.10 & 92 & 68:32 \\
\hline 3 & P3 & Fmoc-allo-pThr(Bn) & DPro & Aib & $\mathrm{Dap}(\mathrm{Ac})-\mathrm{NMe}_{2}$ & $\mathrm{rt}$ & 0.10 & 77 & $85: 15$ \\
\hline 4 & P3 & Fmoc-allo-pThr(Bn) & DPro & Aib & $\mathrm{Dap}(\mathrm{Ac})-\mathrm{NMe}_{2}$ & $\mathrm{rt}$ & 0.04 & 81 & $91: 9$ \\
\hline 5 & P4 & Fmoc-allo-pThr(Bn) & DPro & Aib & $\mathrm{Dap}(\mathrm{Bz})-\mathrm{NMe}_{2}$ & $\mathrm{rt}$ & 0.04 & 65 & $89: 11$ \\
\hline 6 & P5 & Fmoc-allo-pThr(Bn) & DPip & Aib & $\mathrm{Dap}(\mathrm{Ac})-\mathrm{NMe}_{2}$ & $\mathrm{rt}$ & 0.04 & 89 & $87: 13$ \\
\hline 7 & P6 & Fmoc-allo-pThr(Bn) & ${ }^{D} \operatorname{Hyp}(t-B u)$ & Aib & $\mathrm{Dap}(\mathrm{Ac})-\mathrm{NMe}_{2}$ & rt & 0.04 & 82 & $87: 13$ \\
\hline 8 & P7 & Fmoc-allo-pThr(Bn) & DPro & Aib & $\operatorname{Dap}(\mathrm{Ac})-\mathrm{NEt}_{2}$ & rt & 0.04 & 84 & $88: 12$ \\
\hline 9 & P8 & Ac-Fmoc-allo-pThr(Bn) & DPro & Aib & $\mathrm{Dap}(\mathrm{Ac})-\mathrm{NMe}_{2}$ & $\mathrm{rt}$ & 0.04 & 66 & $84: 16$ \\
\hline 10 & P3 & Fmoc-allo-pThr(Bn) & DPro & Aib & Dap(Ac)-NMe 2 & 4 & 0.04 & 79 & $94: 6$ \\
\hline $11^{\dagger}$ & P3 & Fmoc-allo-pThr(Bn) & DPro & Aib & $\operatorname{Dap}(\mathrm{Ac})-\mathrm{NMe}_{2}$ & 4 & 0.04 & 67 & $88: 12$ \\
\hline
\end{tabular}

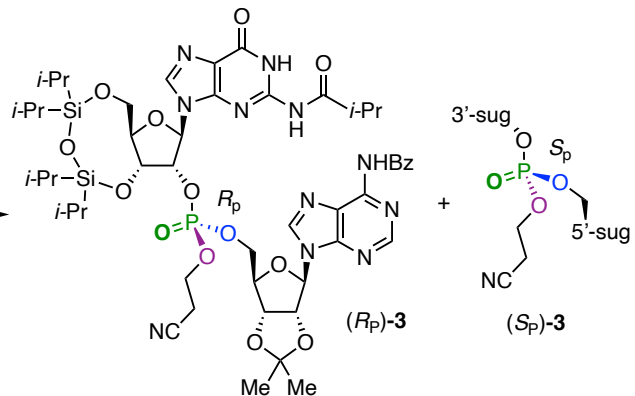

B 'C 2 -type' catalyst optimization

\begin{tabular}{|c|c|c|c|c|}
\hline entry & & catalyst $(\mathrm{Ar}=)$ & Yield (\%) & $\operatorname{dr}\left(S_{\mathrm{p}}: R_{\mathrm{p}}\right)$ \\
\hline 12 & $(R)-\mathbf{B} 1$ & $2,4,6-(i-P r){ }_{3} \mathrm{C}_{6} \mathrm{H}_{2}$ & 26 & 45:55 \\
\hline 13 & (S)-B1 & $2,4,6-(i-\operatorname{Pr})_{3} \mathrm{C}_{6} \mathrm{H}_{2}$ & 74 & 8:92 \\
\hline 14 & (S)-B2 & $3,5-\left(\mathrm{CF}_{3}\right)_{2} \mathrm{C}_{6} \mathrm{H}_{3}$ & 90 & $15: 85$ \\
\hline 15 & (S)-B3 & $4-t-\mathrm{BuC}_{6} \mathrm{H}_{4}$ & 84 & $34: 66$ \\
\hline 16 & (S)-B4 & 4- $\mathrm{MeOC}_{6} \mathrm{H}_{4}$ & 90 & $24: 76$ \\
\hline 17 & (S)-B5 & $2,4,6-\left(\mathrm{CH}_{3}\right)_{3} \mathrm{C}_{6} \mathrm{H}_{2}$ & 71 & $18: 82$ \\
\hline 18 & (S)-B6 & Phenanthr-9-yl & 74 & $13: 87$ \\
\hline 19 & (S)-B7 & $2,4,6-(C y)_{3} \mathrm{C}_{6} \mathrm{H}_{2}$ & 63 & 1:99 \\
\hline 20 & $(R)-\mathrm{B} 7$ & $2,4,6-(\mathrm{Cy})_{3} \mathrm{C}_{6} \mathrm{H}_{2}$ & 80 & 43:57 \\
\hline 21 & DPP & & 79 & $77: 23$ \\
\hline
\end{tabular}

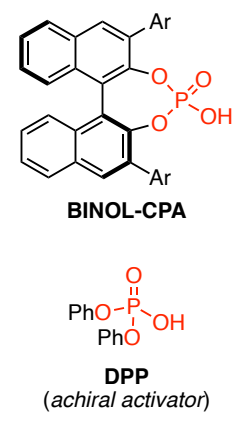

C Demonstration of stereoconvergence diastereomerically pure $\mathbf{1}$
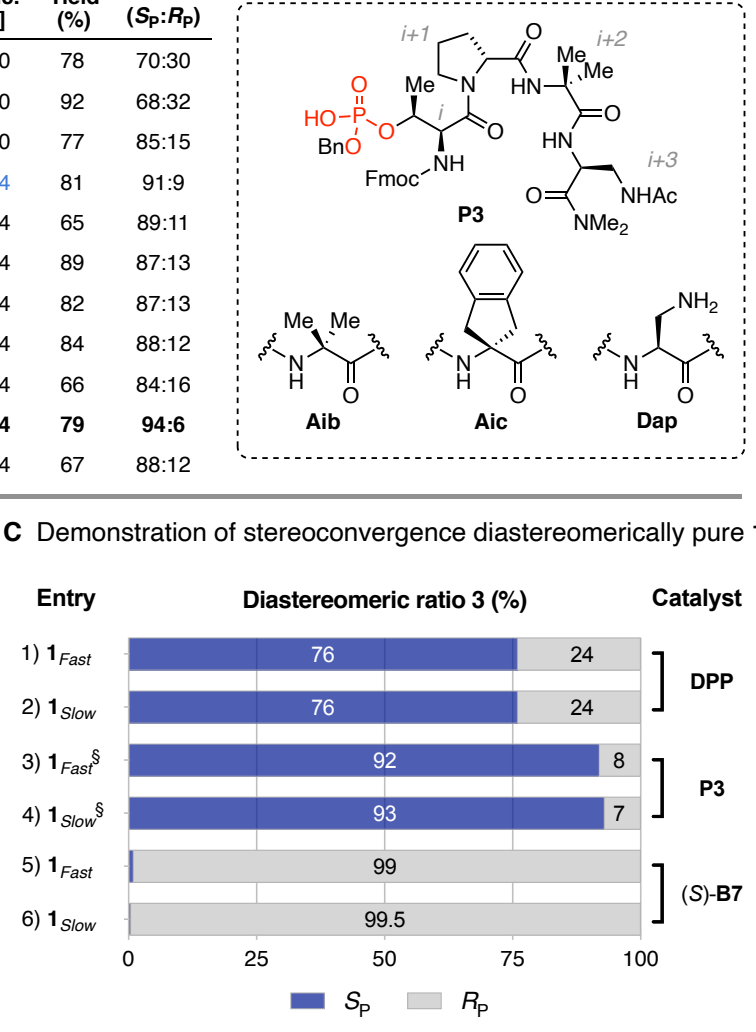

Fig. 2. Catalyst and reaction optimization studies. (A) Optimization of pThr-catalyst favoring $\left(S_{\mathrm{P}}\right)$-3. (B) Optimization of BINOL CPA favoring $\left(R_{\mathrm{P}}\right) \mathbf{3}$ diastereomer. $(\mathbf{C})$ Diastereomeric ratios of $\mathbf{3}$ starting from stereopure phosphoramidite 1. Fast and slow refer to the elution rates of phosphoramidites during purification using reversed phase chromatography. Reactions were performed on $20 \mu \mathrm{mol}$ scale at room temperature unless otherwise noted. Yields and diastereomeric ratios are of isolated material after purification. Yield refers to combined yield of both diastereomers; d.r. determined by ${ }^{1} \mathrm{H}$ nuclear magnetic resonance (NMR) or highperformance liquid chromatography (HPLC) analysis. ${ }^{\dagger}$ Yield and d.r. were determined by ${ }^{31} \mathrm{P}$ analysis of the crude reaction mixture on $50 \mu \mathrm{mol}$ scale. ${ }^{\S}$ Reactions performed at $4{ }^{\circ} \mathrm{C}$. MS: molecular sieves; CE: 2cyanoethyl; [Si] = TIPDS: 1,1,3,3-tetraisopropyldisiloxane; DPP: diphenyl phosphate. 


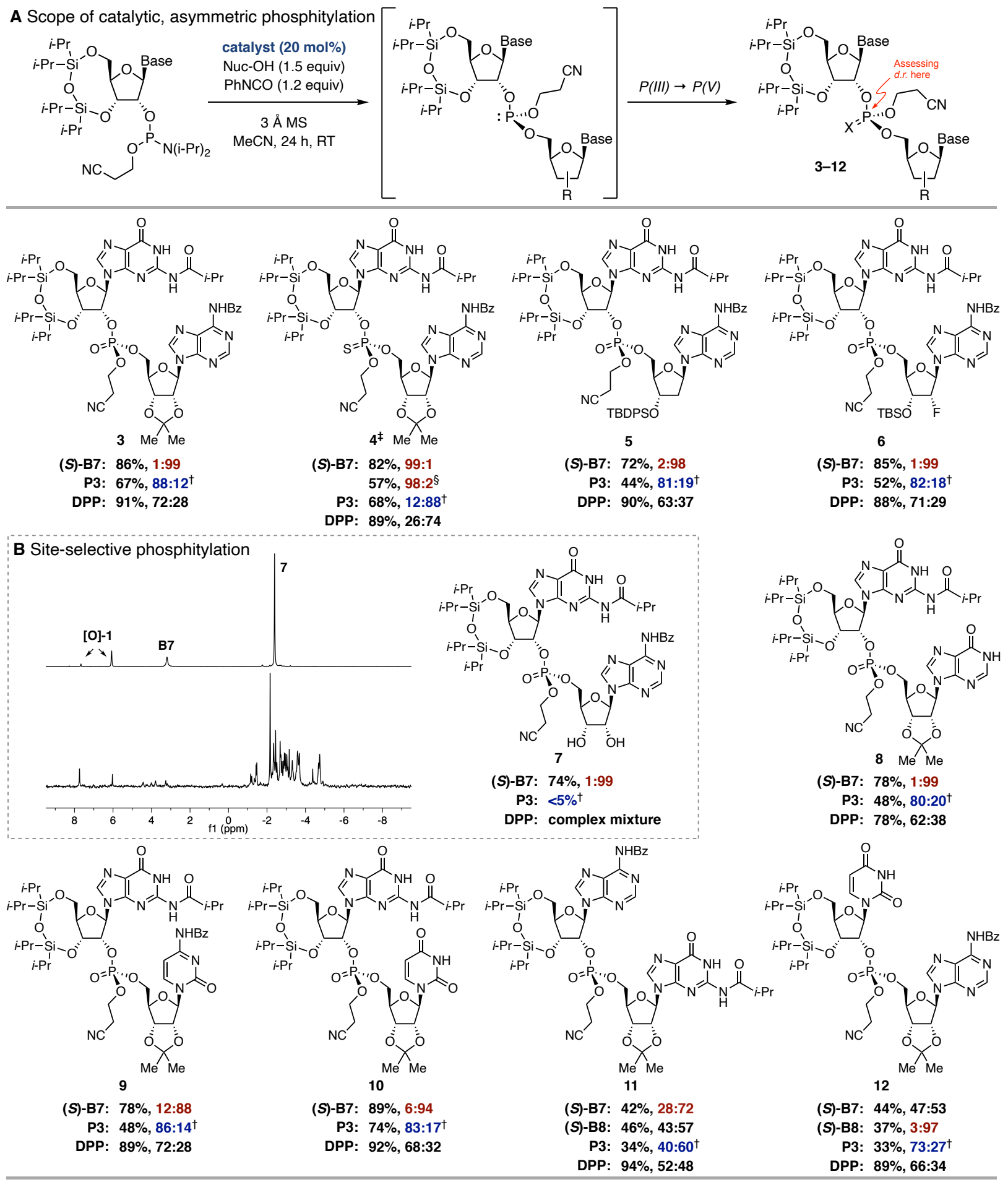

Fig. 3. Substrate scope. (A) Standard conditions: phosphoramidite $(0.05 \mathrm{mmol}), 20 \mathrm{~mol} \%$ catalyst, nucleophile (1.5 equiv), $\mathrm{PhNCO}$ (1.2 equiv), $3 \AA \mathrm{MS}, \mathrm{MeCN}, \mathrm{RT}, 24 \mathrm{~h}$ then $t \mathrm{BuOOH}, 1 \mathrm{~h}$. Yield and diastereoselectivity were determined by quantitative ${ }^{31} \mathrm{P}$ NMR analysis of the crude reaction mixture with internal standard (triphenyl phosphate) and are the average of two trials; $\mathrm{dr}$ refers to the $S_{\mathrm{P}}: R_{\mathrm{P}}$ ratio. ${ }^{\dagger}$ Reactions were performed at $4{ }^{\circ} \mathrm{C}$. †Phenylacetyl disulfide (PADS, 1.2 equiv) was used instead of $t$-BuOOH. ${ }^{\S}$ Reaction was performed on 0.20 mmol scale with $5 \mathrm{~mol} \%(S)$-B7 at $0.40 \mathrm{M}$ in MeCN. (B) ${ }^{31} \mathrm{P}$ NMR analysis of crude dinucleotide 7 using $(S)$ B7 (upper) and DPP (lower). 

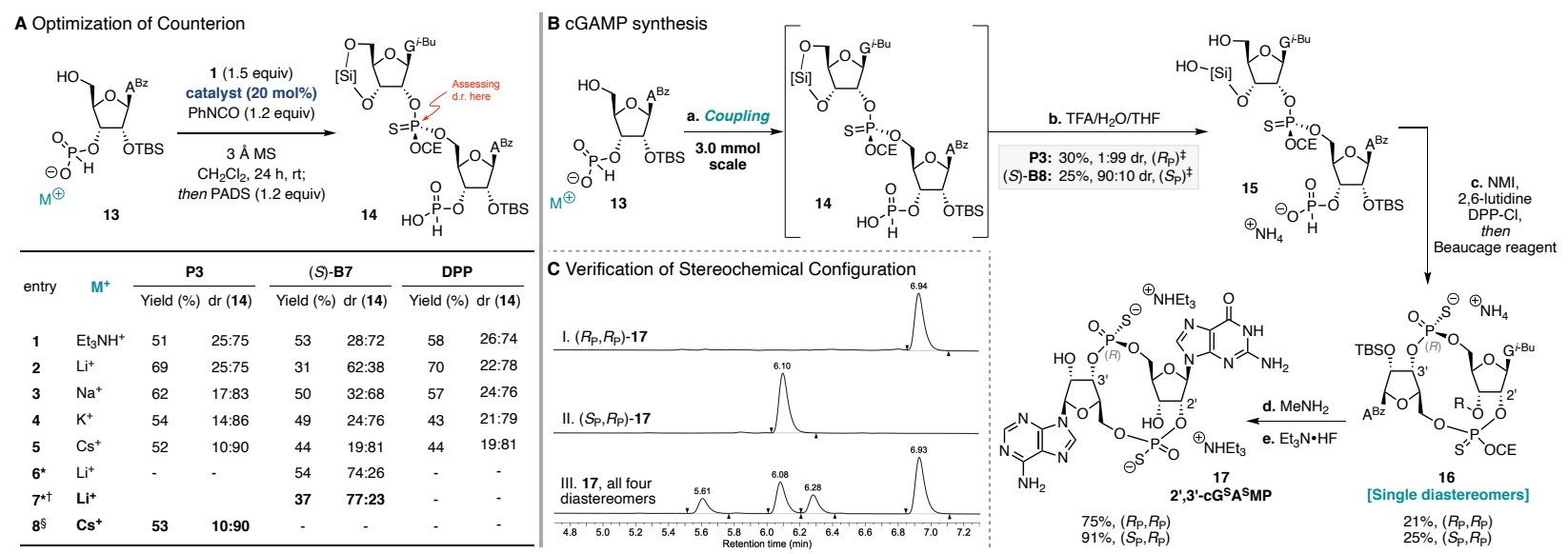

Fig. 4. Gram scale CDN synthesis. (A) Optimization of H-phosphonate counterion. Standard conditions: 1 (0.03 mmol), $20 \mathrm{~mol} \%$ catalyst, nucleophile (1.0 equiv), PhNCO (1.2 equiv), $3 \AA \mathrm{MS}, \mathrm{CH}_{2} \mathrm{Cl}_{2}, \mathrm{RT}, 24 \mathrm{~h}$ then Phenylacetyl disulfide (PADS, 1.2 equiv), $16 \mathrm{~h}$. Yield and diastereoselectivity were determined by quantitative ${ }^{31} \mathrm{P}$ NMR analysis of the crude reaction mixture with triphenyl phosphate as internal standard; dr refers to the $S_{\mathrm{P}}: R_{\mathrm{P}}$ ratio. ${ }^{*}$ Reaction performed with 1.0 equiv 1 in MeCN/DMF $(9: 1 \mathrm{v} / \mathrm{v})$ using $(S)$-B8. ${ }^{\dagger}$ Reaction performed at $4{ }^{\circ} \mathrm{C}$. ${ }^{\S}$ Reaction performed with 1.0 equiv 1. (B) Reaction conditions: a. 1 (1.0 equiv), 13 (1.0 equiv), catalyst (20 mol\%), PhNCO (1.2 equiv), $3 \AA$ MS, 7-48h then PADS (1.2 equiv), 16 h; b. TFA, $\mathrm{H}_{2} \mathrm{O}$, THF, $4{ }^{\circ} \mathrm{C}, 5 \mathrm{~h}$; c. NMI (20 mol\%), 2,6-lutidine (3.6 equiv), DPP-Cl (2.0 equiv), $0{ }^{\circ} \mathrm{C}, 1 \mathrm{~h}$ then Beaucage reagent (3.0 equiv), RT, $30 \mathrm{~min}$; d. $33 \% \mathrm{MeNH}_{2}$ in $\mathrm{EtOH}, 5 \mathrm{~h}$; e. $\mathrm{Et}_{3} \mathrm{~N} \mathrm{HF}$ (5.00 equiv), pyridine, $\mathrm{Et}_{3} \mathrm{~N}, 50{ }^{\circ} \mathrm{C}, 18 \mathrm{~h} .{ }^{\ddagger} \mathbf{1 3}^{\circ} \mathrm{Cs}$ was used with $\mathbf{P 3}$ and $\mathbf{1 3} \cdot \mathrm{Li}$ was used with $(S)$-B8. (C) HPLC analysis $(\lambda 254 \mathrm{~nm})$ of $\mathbf{1 7}$ as a stochastic mixture of diastereomers (bottom trace), $\left(S_{\mathrm{P}}, R_{\mathrm{P}}\right)-\mathbf{1 7}$ (middle trace), and $\left(R_{\mathrm{P}}, R_{\mathrm{P}}\right)-\mathbf{1 7}$ (top trace). A, adenosine; $\mathrm{G}$, guanosine. 